\title{
DA MELANCOLIA À IRONIA: O DISCURSO DISSIMULADO DA CONTEMPORANEIDADE EM BLACK MIRROR
}

\author{
Andréia Shirley Taciana de Oliveira ${ }^{*}$ \\ Danilo França do Nascimento ${ }^{* *}$ \\ Geralda Aparecida do Carmo Schyra ${ }^{* * t}$
}

\begin{abstract}
RESUMO: Analisaremos, neste artigo, o segundo episódio da primeira temporada, Fifteen Million Merits, do seriado britânico Black Mirror. Pretendemos constatar, ao longo desta análise, as características da técnica que estão presentes no cenário, a propagação dissimulada do discurso midiático, o estado de melancolia, o esvaziamento do indivíduo e os traços de ironia que definem os personagens do episódio, tal como acontece com os indivíduos na sociedade contemporânea. Para esta análise, utilizamos os estudos dos teóricos Zygmunt Bauman (2001), Umberto Galimberti (2006), Slavoj Zizek (2011), Giorgio Agamben (2009), Walter Benjamin (apud KHEL, 2010), Soren Kierkegaard (1991) e Lucia Santaella (2008).
\end{abstract}

PALAVRAS-CHAVE: Fifteen Million Merits. Black Mirror. Melancolia. Ironia. Discurso dissimulado.

Com o advento da técnica, ainda que o âmbito das nossas necessidades não tivesse aumentado, são as próprias necessidades elementares que temos em comum com os antigos e os primitivos, como o alimento, o vestuário, a habitação, que exigem, para a sua satisfação, um aparato de interdependência a tal ponto amplo que cancela as personalidades que estão por trás dos respectivos préstimos. (Galimberti, 2006)

Vivemos no mundo da pressa. Ser apressado tornou-se sinônimo de modernidade, de estar conectado com as tecnologias de informação, das quais nos tornamos radares que captam tudo a todo momento e em qualquer lugar, numa rede planetária de apressados em tempo real. Estar à margem disso é estar ultrapassado, preso a um passado com o qual se deseja romper.

\footnotetext{
*Centro Federal de Educação Tecnológica, Belo Horizonte, Brasil. Imeio: astoliveira@gmail.com

${ }^{* *}$ Centro Federal de Educação Tecnológica, Belo Horizonte, Brasil. Imeio: danilofn@gmail.com

*** Centro Federal de Educação Tecnológica, Belo Horizonte, Brasil. Imeio:

gschyra@yahoo.com.br
}

\section{(c) EY-NC-ND}

Esta obra está licenciado com uma Licença Creative Commons. 
É a Idade da técnica ${ }^{1}$, que se fundamenta nas prometidas luzes da ciência, um dos pilares da Modernidade, esta, presidida pela razão, pelo individualismo exacerbado e que produz muitas incertezas. Embora se saiba que a técnica sempre existiu e que sem ela o homem não teria sobrevivido, desde quando fora inventada, destinou-se a recolher, estocar e processar informações numa escala jamais necessitada, nem tampouco disponível. Esta facilidade promovida pela técnica encurta o espaço, o tempo e também produz um discurso de encobrimento dessas incertezas, criando-se uma espécie de fé inabalável no modelo tecnológico. Sua chegada e avanço podem ser vislumbrados através de inúmeras transformações socioestruturais e intelectuais, que se alicerçaram em realidades hoje diferentes, num processo de rupturas com retrocessos e contradições. Tais transformações são o que distingue a Modernidade das outras fases históricas do convívio humano, pois essa se caracteriza pela ideia de "progresso" - compulsiva sede de destruição criativa de desmantelar tudo em nome de se fazer novamente, e pela necessidade de estar-se conectado às redes (Cf. BAUMAN, 2001).

Sob a mesma perspectiva do sociólogo Zygmunt Bauman (2001), o filósofo Umberto Galimberti afirma que "a técnica não tende a um objetivo, não é neutra, não promove sentimento, não redime, não desvenda a verdade, não necessita de sentido, não é uma escolha" (GALIMBERTI, 2006, p. 9). A técnica funciona e aspira à eficiência, ao aperfeiçoamento e à potencialização da própria instrumentalização, tendo em vista que ela está presente em tudo que é manipulado e em que os erros não são tolerados. Somente os humanos erram, as máquinas devem funcionar.

Em função disso, as dicotomias, de natureza política e cultural, são fortalecidas pelo pensamento moderno-ocidental feito de fraturas aprofundadas pela ciência moderna. Corremos não sabemos exatamente para onde. Todavia, como todos estão correndo no mesmo sentido, será esse o caminho certo? Ora, na

\footnotetext{
${ }^{1} \mathrm{O}$ termo "técnica" está associado ao "universo dos meios (as tecnologias), que em seu conjunto compõem o aparato técnico" e à "racionalidade que preside o seu emprego, em termos de funcionalidade". Assim, a técnica "nasceu, não como expressão do espírito humano, mas como remédio à sua insuficiência biológica" (GALIMBERTI, 2006, p. 9).
} 
contemporaneidade, ser capaz de estar no ritmo veloz, de adaptar-se de forma instantânea às novas engenhocas e de saber usá-las o mais rapidamente possível é sinônimo de poder, e isso vicia os indivíduos de tal forma que o virtual passa a ser mais do que o real. Nesta fase, também, identificamos a "fluidez" (BAUMAN, 2001), qualidade dos líquidos e dos gases, que permite com que estes não mantenham sua forma com facilidade, pois estão constantemente prontos (e propensos) a mudá-la. A fluidez apresenta as múltiplas facetas da vida contemporânea, que se divergem e convergem, caracterizadas pela globalização, pela fragilidade dos laços humanos, pelo consumo exacerbado e pela velocidade de movimento que estratifica a sociedade e administra a hierarquia da dominação.

Slavoj Zizek (2011) também critica a pós-modernidade ao afirmar que, na contemporaneidade, a quantidade de informações que são repassadas aos indivíduos, em qualquer hora e lugar, através dos diversos dispositivos tecnológicos, faz com que estes cada vez mais se afastem da natureza, trocando a paisagem natural pela paisagem virtual, residente em algum lugar do espaço. É comum presenciarmos indivíduos juntos em corredores das escolas, lanchonetes, restaurantes, em casa, mas, dialogando com outros indivíduos, virtualmente, através de aparelhos celulares, sem enxergar o outro que está à sua frente. $\mathrm{O}$ "esvaziamento" das relações tornou-se natural e é comum estar-se face a face, mas em silêncio, o qual é apenas rompido pelo som das teclas que se movem incessantemente, procurando no mundo virtual preencher o vazio que atinge os indivíduos contemporâneos. Parafraseando Michel Foucault, citado por Gilles Deleuze (1992), continuamos vivendo numa sociedade de controle: a mass media, cujo controle anterior, através do confinamento, foi substituído pelo controle contínuo do indivíduo por meio da comunicação instantânea. Consequentemente, as interações se iniciam e se desfazem com a mesma facilidade e proporção.

Decerto que a distância e a velocidade que afligem o indivíduo contemporâneo têm proporcionado relacionamentos mediados por dispositivos que detêm o poder e definem o modo pelo qual as pessoas trocam informações, valores econômicos e culturais. Segundo o filósofo Giorgio Agamben, dispositivo se refere "à 
disposição de uma série de práticas e de mecanismos (ao mesmo tempo linguísticos e não-linguísticos, jurídicos, técnicos e militares) com o objetivo de fazer frente a uma urgência" (AGAMBEN, 2009, p. 35). Assim, temos que, neste mundo tomado pela velocidade, a qual repercute nas transações, nas relações afetivas, no caráter descartável dos ídolos e das atitudes, o desejo de se libertar do "sólido" (BAUMAN, 2001) cada vez mais esbarra no aprisionamento imposto pelos dispositivos, o quais, longe de serem flexíveis, ditam as normas que os indivíduos devem seguir, incutem ideias, programam eventos sociais, criam indivíduos irreais, monopolizam as relações, e, por conseguinte, os sentimentos.

A onipresença oferecida pela mídia com o "aqui" e "agora" ("estar em todo lugar e portanto em nenhum lugar") coloca o ser humano como se estivesse a par de tudo no mundo, quando, na verdade, este mundo "já desapareceu por trás da sua representação" (GALIMBERTI, 2006, p. 730). É o que se pode perceber no comportamento cada vez mais notório do indivíduo contemporâneo em relação aos dispositivos tecnológicos, como os smartphones. Cada vez mais as pessoas se "fecham" em seus próprios mundos virtuais, desprezando o contato real com outras pessoas a seu redor, iludidas pelo pensamento equivocado da necessidade do contato globalizado.

Nesse sentido, é que analisaremos, neste artigo, o segundo episódio da primeira temporada, Fifteen Million Merits, do seriado britânico Black Mirror ${ }^{2}$. Pretendemos constatar, ao longo desta análise, as características da técnica que estão presentes no cenário, a propagação dissimulada do discurso midiático, o estado de melancolia e os traços de ironia que definem os personagens do episódio, tal como acontece com os indivíduos na sociedade contemporânea.

Criado por Charlie Brooker, em 2011, Black Mirror é uma série de TV ágil e avassaladora, que se baseia no atual mal-estar ${ }^{3}$ da era contemporânea - o

\footnotetext{
${ }^{2}$ Fonte: < http://www.channel4.com/programmes/black-mirror/>. Acesso em: 30 jan. 2014.

${ }^{3}$ Segundo Maria Rita Kehl (2010), criou-se um novo nome para a expressão do mal-estar herdeira da melancolia pré-freudiana - sentida pelos indivíduos contemporâneos: a depressão. Pois "a ruptura com o paradigma psiquiátrico introduzida por Freud a respeito da melancolia nos força a abandonar este significante e substituí-lo por depressão, como novo nome do sintoma social contemporâneo" (KEHL, 2010, p. 11).
} 
reinado da técnica, influenciada pelas novas tecnologias, a que sucumbe a sociedade atual. Cada série é composta por três episódios de uma narrativa antológica que contam histórias independentes, com elencos diferentes, mas que têm em comum o sentimento de "tecno-paranóia", retratando como as novas tecnologias influenciam a vida e o comportamento dos seres humanos. Ou seja, cada episódio tem um contexto próprio, inclusive uma realidade distinta, embora todos abordem a forma como vivemos e o que poderemos chegar a viver, se não nos atentarmos para o crescente domínio da técnica e do uso excessivo das informações que nos chegam o tempo todo. Sendo assim, através de alertas e profecias soltas, esta série, com roteiros futuristas, episódios independentes e histórias embaladas em futuros distópicos que, na verdade, tratam de problemas bem atuais, prevê destinos apocalípticos para os seres humanos.

Cabe ressaltar que poucas produções para a televisão têm um discurso político tão inteligente e bem articulado como Black Mirror. Entre as histórias vemos críticas às mídias sociais, à exposição da vida privada, à amizade virtual, à futilidade dos pertences virtuais, ao esvaziamento dos indivíduos e ao desmedido processo civilizatório que acomete cada vez a sociedade contemporânea e que nos levam a pensar nesta realidade em que vivemos e em como será nosso futuro devido a essa dependência.

Segundo Brooker, em entrevista ao canal Channel, Black Mirror é "aquele 'espelho negro' que você encontra em toda parede, em cada mesa, na palma de todas as mãos: a tela fria e brilhante de uma TV, de um monitor, de um smartphone". Ou seja, é por meio do monitor, da TV "(...) que se descreve o mundo e se constrói o consenso" (GALIMBERTI, 2006, p. 726). No entanto, "o meio, o medium, não é tanto a televisão, mas a opinião pública, reduzida a espelho de refração do discurso televisivo, no qual se celebra a descrição do mundo" (GALIMBERTI, 2006 p. 727). Em função disso, temos que, muitas vezes, é através dos aparatos tecnológicos que os indivíduos contemporâneos aprendem como amar, comprar, vender, interagir, viver, sentir, ações que antes eram aprendidas com o grupo ao qual se pertencia, como mostram diversas passagens do episódio, mas que hoje são propagadas velozmente pela mídia. 
Diante disso, seria arriscado dizer que estando a técnica em todas as mãos, somos nós, humanos, que, na verdade, somos conduzidos por ela? De acordo com Galimberti (2006, p. 723), "a técnica deixa de ser um meio nas mãos do homem para se tornar um aparato que inclui o homem como seu funcionário". Assim, a técnica e seus aparatos estão em todo lugar, ao alcance do toque dos nossos dedos, propondo-nos modos mais fáceis de resolver os nossos problemas mais simples, como fazer compras, ler um livro, fazer amizades e até encontrar um parceiro romântico. No entanto, ao mesmo tempo em que utilizamos seus préstimos, tornamo-nos dependentes dos aparatos técnicos que promovem o nosso bem-estar ilusório, como nos sinaliza essa série de contos fantásticos sobre os caminhos que a humanidade vem traçando ao longo de seu processo civilizatório.

É nesse ambiente dominado pela técnica que se desenvolve o episódio Fifteen Million Merits, cujo cenário futurista retrata a incomunicabilidade das pessoas, em suas bicicletas, acessando seus jogos e programas preferidos, o que nos remete aos dias de hoje, em que a pressão para se navegar na internet acaba por ilhar cada indivíduo, levando-o ao convívio virtual e ao distanciamento das relações reais. Não obstante, os personagens demonstram um olhar melancólico e desesperançado de obter alguma mudança real que Ihes possa indicar um caminho. De acordo com o dicionário Aurélio (FERREIRA, 2010, p. 527) melancolia significa "tristeza sem causa definida, por vezes acompanhada de saudade; refere-se ao estado em que uma pessoa se encontra sem interesse pelo que está ao seu redor, um estado de profunda apatia e tristeza". Segundo Maria Rita Kehl (2010), a melancolia designa, na cultural ocidental, uma pessoa que está numa posição diferente em relação à norma de sua época. Como um "ser de exceção", o melancólico é analisado, desde Aristóteles, intrinsecamente, de acordo com a criação estética de cada época.

Walter Benjamin foi um dos mais importantes filósofos que analisou o papel da melancolia na sociedade. Benjamin relacionou a melancolia a "um desajuste ou mesmo a uma recusa quanto às condições simbólicas do laço social" (KEHL, 
2010, p. 2). O autor ainda define a melancolia como acedia, um termo do latim que se refere à negligência do coração, causando a desvalorização das atividades humanas. A fatal consequência desta desvalorização é uma total submissão à ordem que impera no mundo, de acordo com o que afirma Kehl (2010, p. 10):

\begin{abstract}
Sua famosa frase: "nunca há um documento da cultura que não seja, ao mesmo tempo, um documento da barbárie" expressa perfeitamente o pessimismo de Benjamin em relação às ideologias do progresso (tão caras ao nosso tempo), que se sustentam à custa do esquecimento das vítimas da história. Para ele, mesmo a ideia de revolução é indissociável da recuperação do passado, pois não há emancipação que se sustente à custa do esquecimento (ou do recalque) das lutas e derrotas de nossos antepassados.
\end{abstract}

Esta "traição" no sentido de se esquecer das vítimas do passado favorece o sentimento de melancolia tão comum na contemporaneidade, baseado na desvalorização das atividades humanas, na deslealdade entre os homens para que haja lealdade nas relações de poder, na sensação de um mundo vazio, e na mera materialização das relações humanas (KEHL, 2010, p. 11). Nesse sentido, o episódio Fifteen Million Merits de Black Mirror evidencia o pouco valor encontrado entre as atividades humanas, como se pode notar nas cenas em que um dos personagens humilha deliberadamente os funcionários da limpeza, chamando-os de "porcos", ou mesmo nas cenas do programa de talentos Hot Shots (do mesmo estilo de "Britain's Got Talent", no Reino Unido, ou de "Qual é o seu Talento", no Brasil), em que as humilhações exercidas pelos jurados aos participantes são transmitidas a todos por meio do ciberespaço. O futuro que este episódio apresenta não está tão longe dos tempos atuais, visto ser comum perceber a coisificação das relações humanas na atualidade, quando o dinheiro e os bens materiais muitas vezes exercem um papel cada vez mais importante na vida das pessoas. Assim, não é difícil entender porque a depressão, doença psiquiátrica relacionada à melancolia, tornou-se tão evidente na vida contemporânea.

Outro aspecto apresentado no episódio Fifteen Million Merits diz respeito ao que Benjamin afirma sobre a fatal consequência desta desvalorização das atividades humanas: a total submissão à ordem que impera no mundo. Neste episódio, todas 
as pessoas vivem de acordo com o que o sistema virtual designa para as suas vidas, tornando-se assim meras ferramentas das relações de poder. Este sistema de aprisionamento leva todos que trabalham nas bicicletas a sonharem com uma vida melhor, livre, que só é possível se eles conseguirem participar do humilhante programa de talentos e ainda agradar aos maldosos jurados, que ditam as regras nesse local. As cenas do local de trabalho também são interessantes por mostrar momentos de individualismo ${ }^{4}$ entre os personagens que pedalam nas bicicletas a fim de gerar energia e adquirir méritos. Durante as cenas, os indivíduos, com suas roupas de cor cinza, se encontram numa sala repleta de bicicletas, todas equipadas com uma tela à sua frente, que são ligadas quando cada personagem senta em sua bicicleta, ou seja, por meio do contato humano, o dispositivo das telas é ligado, a fim de efetivar o controle das mentes e dos corpos, via execução de programas cuja representação de mundo reafirma a instantaneidade da sociedade contemporânea. Nesse sentido, Galimberti afirma que

\begin{abstract}
a representação do mundo oferecida pela mídia altera a presença, não só porque impede um real contato com o mundo, mas também porque, contraindo a sucessão temporal na instantaneidade do presente, a extensão espacial na pontualidade do ponto de observação priva o homem daquela dimensão espaço-temporal que até agora esteve na base da sua experiência do mundo. (GALIMBERTI, 2006, p. 728. Grifos do autor).
\end{abstract}

Além disso, podemos observar de que forma se difunde, no episódio, o discurso midiático dissimulado que atormenta ininterruptamente os personagens constantemente ligados às imagens refletidas pelos espelhos, mesmo eles estando em seus quartos, onde deveriam ter privacidade. Parafraseando Galimberti (2006), é reunindo na tela todos os acontecimentos que se pode simular a ideia de que se está em todo lugar e que o distante está próximo, ainda que virtualmente. Isso se configura como uma das características determinantes do processo dissimulado contemporâneo que tem por objetivo a propagação desmedida do discurso midiático. Não há silêncio ou paz para se estar sozinho com os próprios pensamentos. Estes são sempre moldados pelas informações e

\footnotetext{
${ }^{4}$ Para Bauman, a modernidade é época em que a vida social passa a ter como centro a existência do individualismo. É fase marcada por uma expansiva autonomia do homem em relação à vida social. (BAUMAN, 2001).
} 
propagandas exibidas nas telas, uma tendência cada vez mais presente na vida contemporânea, na medida em que

\begin{abstract}
hoje o mundo acontece porque é comunicado, e o mundo comunicado é o único no qual habitamos. Não mais um mundo de fatos e depois a informação, mas um mundo de fatos pela informação. Só o silêncio restituiria ao mundo a sua genuinidade. Mas ele não é mais possível. $\mathrm{E}$, assim, o que se estava perfilando sob o registro inocente da informação torna-se eminente da construção do verdadeiro e do falso, não porque os meios de comunicação mentem, mas porque nada é feito senão para ser comunicado. O mundo se resolve na sua narração. (GALIMBERTI, 2006, p. 726. Grifos do autor).
\end{abstract}

Em função disso, podemos ressaltar que, no episódio Fifteen Million Merits, os personagens são "contaminados" o tempo todo por informações e propagandas que aparecem repentinamente, muitas vezes de forma inconveniente. Tais interferências midiáticas fazem com que os personagens do episódio não tenham contato com outros discursos e ideias, tornando-se, assim, "presos" num sistema autoritário e limitador que admite apenas o que é tido como gerador de lucro e exclui o que é considerado como lixo.

O principal personagem da história é o jovem negro Bing ${ }^{5}$ Madsen (Daniel Kaluuya), que vive e trabalha numa empresa que gera energia para o funcionamento das máquinas, através das pedaladas de seus operários. Não é por acaso que, no episódio, o homem surge como um complemento da máquina, cujo trabalho é produzir velocidade. De acordo com Alain Badiou (2007), o pensamento atual é criar um novo homem, cada vez mais capitalista, técnico, veloz, desprendido de raízes e de sua cultura e em constante busca do lucro e de superação; um "homem-máquina” como pressupõe Paul Virilio (2000). Destarte, como pode ser vislumbrado no episódio e também na realidade, até mesmo a vida social e intelectual dos indivíduos é reduzida a um sistema de reflexos condicionados e mecanizados, como acordar, trabalhar, dormir e comunicar, que se realiza através do mágico toque das pontas dos dedos.

\footnotetext{
${ }^{5}$ Bing, nome de origem americana que significa cortês, refinado. Fonte: < http://www.significadonomes-bebes.com/n/Bing >. Acesso em: 30 jan. 2014.
} 
Vale ressaltar que, durante o episódio, os personagens passam a maior parte do tempo em suas bicicletas e à medida que as pedaladas são realizadas, são creditados bônus em uma tela eletrônica. Dependendo do gosto e da escolha de programas e jogos, ganham-se ou perdem-se méritos (a moeda local). Os pontos acumulados podem ser trocados por brindes, em sua maioria, virtuais - roupas, alimentos, temas, programas de TV - , o que nos permite fazer uma analogia com o consumismo tão evidente na sociedade atual. Os créditos também podem ser usados para assistir ou ignorar anúncios banais e/ou programas eróticos, que aparecem a qualquer momento nas telas dos quartos dos personagens, nos espelhos negros/TVs que ficam na frente das bicicletas e em quaisquer das várias telas que rodeiam os indivíduos o tempo todo, algo que faz uma alusão ao que se resume, em sua maioria, à programação de TV americana e também brasileira. Ou seja, somos acometidos por propagandas abusivas e intrusivas, que menosprezam a nossa inteligência e nos iludem de que estamos cercados por uma gama de maravilhas, bastando, apenas, um toque para que tudo esteja à nossa disposição. Tais programas e propagandas não valorizam a vida dos menos favorecidos, dos excluídos ou daqueles que precisam lutar para continuar vivendo nessa "selva midiática" em que se tornou a sociedade contemporânea.

É importante analisar também o estado do corpo físico e mental do indivíduo que vivencia uma relação intensificada com a tecnologia por meio de uma tela, conforme se pode notar nos personagens durante as cenas do episódio Fifteen Million Merits. Para pensar sobre este aspecto, os estudos de Lucia Santaella (2008) sobre o corpo sensório-perceptivo do cibernauta são uma importante fonte. Santaella afirma que há uma crença comum de que o corpo do internauta fique completamente inerte quando está de frente à tela do computador, mas que,

por trás da aparente imobilidade corporal do usuário plugado no ciberespaço, há uma exuberância de instantâneas reações perceptivas em sincronia com operações mentais. Estão em atividade mecanismos cognitivos dinâmicos, absorventes, extremamente velozes, frutos da conexão indissolúvel, inconsútil, do corpo sensório-perceptivo à mente, sem os quais o processo perceptivo-cognitivo inteiramente novo da navegação não seria possível (SANTAELLA, 2008, p. 37). 
A interatividade entre o usuário e a tecnologia está muito além de meros cliques de mouse, ou mesmo de gestos em frente à tela, conforme é evidenciado no episódio, o qual não representa uma realidade distante, visto que muitos dispositivos tecnológicos já possuem tal opção de interatividade (como o videogame Xbox 360). De acordo com Santaella (2008, p. 52), "quando se navega no ciberespaço, por fora, o corpo parece imóvel, mas, por dentro, uma orquestra inteira está tocando instrumentos não apenas mentais, mas, ao mesmo tempo, numa coordenação inconsútil, perceptivos, sensórios e mentais". É notável a complexidade do estado corporal de Bing neste episódio de Black Mirror em relação aos "espelhos negros" a sua volta. Tal relação pode ser tanto positiva, como as facilidades do dia-a-dia (conseguir por meio de apenas alguns gestos um pouco de pasta de dente, apesar das propagandas), quanto negativa, como uma forma de controle (quando Bing fecha os olhos para a propaganda e no mesmo instante aparece um aviso sonoro irritante com a mensagem "Retomar visualização").

Todavia, de acordo com o enredo do episódio, a grande chance de mudar de vida é participar de um programa de calouros a que todos assistem cujas "cartas" já se encontram definidas, ou seja, em que há pessoas predeterminadas a seguir um roteiro. Ora, no reino da técnica, a possibilidade de mudar de vida via programa de televisão não é um absurdo, pois cada vez mais as pessoas estão dispostas a participarem de reality show e a tornarem públicas suas pessoalidades, seus sentimentos, suas ações e percepções, para obter fama e dinheiro.

Logo, é nesse momento que se inicia a escalada do tema rumo ao seu ápice, quando Bing conhece uma colega: $\mathrm{Abi}^{6}$ Khan (Jessica Brown Findlay). Ao ouvi-la cantar no banheiro, ele se apaixona por ela e por sua doce voz. Então, Bing resolve doar seus méritos, adquiridos por herança de seu irmão, para que ela realize seu sonho de ser cantora, no programa de talentos Hot Shots, pelo preço de quinze milhões de méritos. Contudo, a participação de Abi no programa não se dá como esperado. Persuadida pelo discurso dissimulado da mídia, por meio

6 Abi, nome de origem hebraica que significa força de vontade, originalidade. Fonte: < http://www.significado.origem.nom.br/nomes/abi.htm>. Acesso em: 30 jan. 2014. 
da ironia dos jurados e dos espectadores do programa, ela se vê insegura e incapaz de renunciar às promessas tecnológicas. Segundo o dicionário Aurélio, ironia é "figura de linguagem, geralmente, usada para fazer graça ou mostrar irritação, em que se declara o contrário do que se pensa. Acontecimento ou desfecho contrário ao que se esperaria das circunstâncias" (FERREIRA, 2010, p. 467). Sendo assim, a ironia carrega diversas possibilidades de interpretação, de incertezas significativas e ambíguas. Quando aplicada no uso corrente da linguagem, estabelece uma relação inesgotável de hiperonímia entre termos que se confundem com dissimulação, hipocrisia, fingimento e mentira. Para o filósofo Soren Kierkegaard (1991, p. 215), ironia é "figura do discurso retórico, cuja característica está em se dizer o contrário do que se pensa". Sendo assim,

\begin{abstract}
a ironia, como extensão do ponto de vista reflexivo e crítico do sujeito diante da realidade que o circunda, atesta a própria incapacidade da linguagem em representar qualquer experiência centrada na realidade dada, pois, por trás do papel, não existe o mundo real, mas a imensidão que se dá além da escritura. (KIERKEGAARD, 1991, p. 215).
\end{abstract}

Ou seja, o sujeito que se submete ao jogo irônico angustia-se diante da descoberta de que a realidade não tem um sentido único ou não é imediatamente legível. Nesse sentido, no episódio, a ironia usada pelos jurados para persuadir a personagem funciona como um dispositivo do discurso midiático, cuja função é convencer a ela e aos espectadores do programa de que o que os jurados propõem é o melhor para ela. Abi, então, é arrebatada pelo sistema, tornando-se mais uma peça do jogo fáustico ${ }^{7}$ da contemporaneidade, cujo propósito é se desenvolver sempre e cada vez mais. Ou seja, não há limites para a técnica. Ela preside tudo. Quem não se adéqua é excluído.

No entanto, o desfecho trágico de Abi promove uma reviravolta na vida de Bing, levando-o a perceber que também precisa mudar de vida. Afinal, essa é uma das funções da mídia: "modelar necessidades e desejos a partir daquilo que é quotidianamente oferecido e consumido [...], de modo que cada um não deseje

\footnotetext{
${ }^{7}$ Fausto é um drama trágico filosófico que narra a procura incessante de um homem em busca do progresso. Cf. O Fausto de Goethe: a tragédia do desenvolvimento, do livro "Tudo que é sólido se desmancha no ar: a aventura da modernidade" (1986), de Marshall Berman.
} 
nada mais do que lhe é destinado receber" (GALIMBERTI, 2006, p.733). Diante disso, Bing pedala sem parar para acumular pontos e participar do programa de calouros. Quando consegue, ele tenta persuadir os jurados do Show de talentos, ao ministrar um discurso que diz que todos têm direito à liberdade, a começar pelas mais simples, como comer uma fruta ou observar a natureza. Assim, ele tenta assegurar um processo de contra-hegemonia em defesa dos interesses da classe dos operários, ao defender outra forma de pensar, agir e sentir na sociedade em que vivem. Mas, tudo em vão. Inicialmente, ele consegue chamar a atenção dos espectadores e dos jurados para o seu discurso, mas, em seguida, Bing também é vencido pelo sistema e termina por propagá-lo, minando, em quem assiste ao episódio, qualquer esperança de que o humano sobressairá à técnica. O final do episódio evidencia que a "libertação" de Bing em relação ao sistema de bicicletas apenas se resume a outro tipo de "aprisionamento", em que, com um pouco mais de conforto, ele permanece vigiado pelos espelhos negros que continuam controlando e limitando a sua vida. Ou seja, não há como escapar da técnica.

A partir dessas reflexões, podemos indagar: que tipo de liberdade se pode encontrar na era tecnológica? A partir da análise desse episódio da série Black Mirror, constata-se que, no cenário contemporâneo, o domínio da técnica sobre os seres humanos é denunciado a partir da melancolia dos personagens diante de suas relações insípidas, da ironia dos jurados, da ausência de sentimentos, da presença do individualismo, do discurso dissimulado da mídia, do controle dos corpos, bem como da presença da liberdade impessoal, "[...] na qual o sentimento de liberdade se reduz à pura e simples mudança das obrigações" (GALIMBERTI, 2006, p. 66). É nessa perspectiva que se verifica a mudança de vida sofrida por Bing, que passou de uma "prisão" num sistema manual de trabalho com bicicletas para outra "prisão" do mesmo sistema virtual, porém com um pouco mais de conforto, ao se tornar apresentador e propagador do discurso dissimulado da contemporaneidade. Nesse sentido, o enredo explora bem todas as situações hiper dimensionadas que a realidade tecnológica desencadeia, mas também põe em foco o mais sublime dos sentimentos, o amor. Trata-se de uma tônica, aliás, recorrente em Black Mirror, cujos episódios apresentam histórias distantes que 
sempre recaem em algo atual, permitindo o vislumbre de uma esperança que comumente se evidencia pelo sentimento de amor.

Em Fifteen Milion Merits, na escuridão do espelho negro, a esperança ressurge através do sonho, do amor. Não é por acaso que a música tema do episódio é $I$ have a dream (Eu tenho um sonho), do Abba. Esta canção anuncia que os sonhos ajudam as pessoas a enfrentarem qualquer coisa e que por isso elas devem agarrar-se ao futuro que podem vislumbrar. Assim, ela nos empurra através da escuridão, pois ainda há mais uma milha de realidade a atravessar.

Mas, e fora da ficção, o que devemos fazer? Recorrermos à luz da poesia, que sensibiliza os homens e aponta caminhos, através dos devaneios dos poetas? Discutirmos, a partir de reflexões dos filósofos que nos têm alertado sobre o futuro sombrio da humanidade para o qual caminhamos? A poesia, como instrumento capaz de transportar o indivíduo do real para um mundo imaginário mais próximo dos deuses e da natureza, tem voz sensibilizadora, no sentido de dizer, através dos versos, os males que afetam a sociedade e de tentar,a partir disso, buscar uma luz. Nesse sentido, temos a poesia como caminho, onde não há somente retas, mas curvas e retornos. Assim, também deve caminhar o indivíduo contemporâneo: avante, sem suspender o passo. Contudo, sem deixar de enxergar as fraturas do seu tempo e de viver profundamente seus projetos, renovando-se a cada dia, para sempre e enquanto dure, sem pressa de viver e nem de morrer. Discutir, portanto, vislumbra-se como um dos preceitos da Filosofia, cujo objetivo é debater sobre as coisas e os seres, sem que com isso se chegue a uma inquestionável solução. Importa, apenas, discursar sobre os males contemporâneos e divulgá-los, o máximo possível, para, além de provocar, levar aos indivíduos conhecimento e reflexão sobre as questões que estão imbricadas na técnica e que fortalecem a sociedade do controle. Isso porque, àqueles que empunham o conhecimento caberá a tarefa de fazer com que os indivíduos se reapropriem dele, na medida em que estão cientes de que o conhecimento é um dos construtores à altura da tarefa de erigir uma nova, quiçá melhor, sociedade.

\section{FROM MELANCHOLIA TO THE IRONY: THE COVERT DISCOURSE OF CONTEMPORANEITY IN BLACK MIRROR}

Texto Digital, Florianópolis, Santa Catarina, Brasil, v. 10, n. 2, p. 25-40, jul./dez. 2014. ISSNe: 1807-9288. 
ABSTRACT: We will analyze in this article the Black Mirror's second episode of the first season, Fifteen Million Merits. We intend to observe, throughout this analysis, the technical characteristics that are present in the scenario, the covert propagation of media discourse, the state of melancholia, emptying the individual, and the traces of irony that define the characters in the episode, as with individuals in contemporary society. For this analysis, we used the theoretical studies of Zygmunt Bauman (2001), Umberto Galimberti (2006), Slavoj Žižek (2011), Giorgio Agamben (2009), Walter Benjamin (cited Khel, 2010), Soren Kierkegaard (1991) and Lucia Santaella (2008).

KEYWORDS: Fifteen Million Merits. Black Mirror. Melancholia. Irony. Covert discourse.

\section{Referências}

AGAMBEN, Giorgio. O que é o contemporâneo? e outros ensaios. Chapecó: Argos, 2009.

BADIOU, Alain. O século. São Paulo: Ideias e Letras, 2007, p. 9-23.

BAUMAN, Zygmunt. Modernidade líquida. Rio de Janeiro: Jorge Zahar Editor, 2001.

BLACK MIRROR. 15 Million Merits. Escrito por: Charlie Brooker, Kanak Huq. Dirigido por: Euros Lyn. Reino Unido, 2011.

BERMAN, Marshall. Tudo que é sólido se desmancha no ar: a aventura da modernidade. São Paulo: Companhia das Letras, 1986.

DELEUZE, Gilles. Conversações. São Paulo: editora 34, 1992, p. 209-218.

FERREIRA, Aurélio Buarque de Holanda. Novo dicionário da língua portuguesa. 8. ed. Curitiba: Positivo, 2010.

GALIMBERTI, Umberto. Psiche e techne: o homem na idade da técnica. São Paulo: Editora Paulus, 2006.

KEHL, Maria Rita. A melancolia em Walter Benjamin e em Freud. III Seminário Internacional Políticas de la Memória. 2010. Buenos Aires, Argentina. Disponível em: <http://conti.derhuman.jus.gov.ar/2010/10/seminario.shtml>. Acesso em: 22 jan. 2014.

KIERKEGAARD, Sören. O conceito de ironia. Petrópolis: Vozes, 1991.

SANTAELLA, Lúcia. Corpo e comunicação: sintoma da cultura. 3. ed. São Paulo: Editora Paulus, 2008.

VIRILIO, Paul. A Velocidade da libertação. Lisboa: Relógio d'água, 2000.

ZIZEK, Slavoj. Prefácio à edição brasileira. In: Primeiro como tragédia, depois como farsa. Tradução Maria Beatriz de Medina. São Paulo: Boitempo, 2011. p. 7-14. 
Texto recebido em: 05/09/2014.

Texto aceito em: 01/12/2014. 